\title{
Stabilisation of Volcanic Dark Magnesium Clay using Lime
}

\author{
Rajeshwar Goodary ${ }^{1}$, Miraniaina Adriamalala², Roodheer Beeharry ${ }^{1}$, Anoop Aujayeb ${ }^{1}$ \\ ${ }^{1}$ Université des Mascareignes \\ Avenue de la Concorde, Rose Hill, Mauritius \\ rgoodary@udm.ac.mu; rbeeharry@udm.ac.mu \\ ${ }^{2}$ Institut Supérieur de Technologie d'Antananarivo, Antananarivo, Madagascar \\ miraniaina2@yahoo.fr
}

\section{Extended Abstract}

New development for a fast growing economy requires appropriate infrastructure and the mass exploitation of areas underlain by problematic soils is inevitable. Recent structural disorders due to soil movement in existing roads and buildings in these areas call for an urgent particular study of these formations, in order to mitigate such damages in future.

In this study, a family of widespread expansive soil, namely Dark Magnesium Clay of the Lauzun family [1] comprising essentially montmorillonite clay particles, sampled from the Port Louis Ring Road Phase I project, is stabilized with variable lime content and the strength properties are investigated. Optimal lime content to yield maximum characteristic compressive strength at the age of 21 days is determined. The test specimens are prepared at maximum dry density (MDD) value, obtained from the standard Proctor compaction test, in compliance with BS 1377 [2].

Raw lime, acquired from local retailers, based in Mauritius, is used to prepare various trial mixes at $0 \%, 2.5 \%, 5 \%$, $7.5 \%, 10 \%, 12.5 \%$ and $15 \%$ lime content. The soil and lime are mixed in a mechanical mortar mixer with a fixed rotational speed of the helix for a duration of 5 minutes. Water is then added and mixed for an additional 10 minutes [3]. For each mix, a set of three cubical specimens $40 \mathrm{~mm}$ x $40 \mathrm{~mm}$ x $40 \mathrm{~mm}$ are prepared in a mould with dimensions $40 \mathrm{~mm}$ x $40 \mathrm{~mm}$ and $40 \mathrm{~mm}$ high. The maximum dry density obtained from the standard Proctor compaction test is $1.437 \mathrm{~g} / \mathrm{cm}^{3}$ with a corresponding optimum moisture content (OMC) value equal to $30.5 \%$. The soil under investigation is classified as highly plastic with potential swelling and shrinkage properties (liquid limit $=53.4 \%$, plastic limit $=27.2 \%$ and plasticity index $=26.2 \%$ ).

The mass of specimen required to fill the mould each time is defined as a function of the maximum dry density and the volume of mould which gives a mass of $\mathrm{Mg}$ of soil mix to be pressed in the mould at OMC to achieve $1.437 \mathrm{~g} / \mathrm{cm}^{3} \mathrm{MDD}$. The mass of soil and water needed for each increment of lime content is kept constant. An average compaction pressure of $8 \mathrm{MPa}$, which is possibly the equivalent proctor energy, was required to press the samples until they achieve $40 \mathrm{~mm}$ height [4]. The samples are demoulded and allowed to cure in a water-saturated and airtight container for 7 days at room temperature. After this period, samples are allowed to cure at ambient room temperature [5] and are then tested for their unconfined compressive strength at the age of 21 days.

Results show that an addition of $7.5 \%$ of lime is adequate to yield a maximum unconfined compressive strength value of 5.5 MPa with a decrease in linear shrinkage value from $12.1 \%$ to $6.1 \%$ or rather by $50 \%$, allowing to conclude that an addition of an optimum amount of lime helps to improve the packing structure of the soil mass under study, thus improving its mechanical behaviour.

Keywords: Dark magnesium clay, lime, Proctor compaction, curing, compressive strength, linear shrinkage

\section{References}

[1] V. Proag, The geology and water resources of Mauritius. Mahatma Gandhi Institute, 1995.

[2] British Standards BS 1377, Methods of tests for soils for civil engineering purposes, 1990.

[3] R. Goodary, et al., "Investigation of the strength properties of cement stabilised soils of volcanic origin," Construction and Building Materials, vol. 28, pp. 592-598, 2012. 
[4] R. Goodary et al, "Effect of Fly ash on Strength and Compressibility of Dark Magnesium Clay," in Proceedings 'Advances in Civil Engineering for Sustainable Development', Thailand, pp. 437-442, 2014.

[5] S. Horpibulsuk, et al, "Analysis of strength development in cement stabilised silty clay from microstructural considerations," Construction and Building Materials, vol. 24, pp. 2011-2021, 2010. 